ORIGINAL ARTICLE

\title{
A role for D-aspartate oxidase in schizophrenia and in schizophrenia-related symptoms induced by phencyclidine
} in mice

\author{
F Errico ${ }^{1,2,11}$, V D'Argenio ${ }^{1,2,11}$, F Sforazzini ${ }^{3,11}$, F lasevoli ${ }^{4}$, M Squillace ${ }^{1}$, G Guerri ${ }^{1}$, F Napolitano ${ }^{1,2}$, T Angrisano ${ }^{2,5,6}$, A Di Maio ${ }^{1}$, \\ S Keller ${ }^{2,5}$, D Vitucci ${ }^{1}$, A Galbusera ${ }^{3}$, L Chiariotti ${ }^{2,5}$, A Bertolino ${ }^{7,8}$, A de Bartolomeis ${ }^{4}$, F Salvatore ${ }^{1,2,9}$, A Gozzi ${ }^{3,12}$ and A Usiello $^{1,10,12}$
}

Increasing evidence points to a role for dysfunctional glutamate $N$-methyl-D-aspartate receptor (NMDAR) neurotransmission in schizophrenia. D-aspartate is an atypical amino acid that activates NMDARs through binding to the glutamate site on GluN2 subunits. D-aspartate is present in high amounts in the embryonic brain of mammals and rapidly decreases after birth, due to the activity of the enzyme D-aspartate oxidase (DDO). The agonistic activity exerted by D-aspartate on NMDARs and its neurodevelopmental occurrence make this D-amino acid a potential mediator for some of the NMDAR-related alterations observed in schizophrenia. Consistently, substantial reductions of D-aspartate and NMDA were recently observed in the postmortem prefrontal cortex of schizophrenic patients. Here we show that DDO mRNA expression is increased in prefrontal samples of schizophrenic patients, thus suggesting a plausible molecular event responsible for the $\mathrm{D}$-aspartate imbalance previously described. To investigate whether altered D-aspartate levels can modulate schizophrenia-relevant circuits and behaviors, we also measured the psychotomimetic effects produced by the NMDAR antagonist, phencyclidine, in Ddo knockout mice $\left(D d o^{-1-}\right)$, an animal model characterized by tonically increased $\mathrm{D}$-aspartate levels since perinatal life. We show that $D d 0^{-/-}$mice display a significant reduction in motor hyperactivity and prepulse inhibition deficit induced by phencyclidine, compared with controls. Furthermore, we reveal that increased levels of D-aspartate in $\mathrm{Ddo}^{-1-}$ animals can significantly inhibit functional circuits activated by phencyclidine, and affect the development of cortico-hippocampal connectivity networks potentially involved in schizophrenia. Collectively, the present results suggest that altered D-aspartate levels can influence neurodevelopmental brain processes relevant to schizophrenia.

Translational Psychiatry (2015) 5, e512; doi:10.1038/tp.2015.2; published online 17 February 2015

\section{INTRODUCTION}

Schizophrenia (SCZ) is a chronic and severe mental illness with a prevalence of $0.5-1 \%$. Although the exact pathophysiological determinants of this disabling condition remain poorly understood, converging evidence points to a role for developmental dysfunction of glutamate neurotransmission involving $N$-methyl-Daspartate receptors (NMDARs). ${ }^{1-4}$ Consistent with this hypothesis, postmortem studies have shown alterations in NMDAR-related protein and gene expression ${ }^{5}$ and metabolic pathways involving glutamate/NMDAR modulatory compounds such as $\mathrm{N}$-acetylaspartylglutamate and D-serine (D-Ser). ${ }^{6-9}$ The ability of NMDAR antagonists (for example, ketamine and phencyclidine (PCP)) to elicit SCZ-like symptoms in humans and animals provide robust pharmacological support for this theory.,10,11 However, the molecular events underlying glutamatergic impairment associated with this disease remain unclear. ${ }^{12}$

Free D-aspartate (D-Asp) is present in markedly high amounts in the embryonic brain of mammals. After birth, the endogenous levels of this atypical amino acid rapidly decrease, ${ }^{13-16}$ due to the onset of the D-aspartate oxidase (DDO) activity. ${ }^{17}$ Recent evidence has shown that D-Asp activates NMDARs through the binding to the glutamate site of GluN2 subunits. ${ }^{18}$ Consistently, experimental approaches aimed at increasing endogenous content of D-Asp in mice have demonstrated that D-Asp modulates a number of NMDAR-mediated processes. For example, both adult knockout mice for the Ddo gene (Ddo-l-) and D-Asp-treated animals show increased NMDAR-related synaptic plasticity and memory, ${ }^{18-21}$ as well as augmented spine density and dendritic length in the hippocampus and prefrontal cortex (PFC). ${ }^{22}$ In keeping with the animal data, a single-nucleotide polymorphism within the human $D D O$ gene predicts reduced expression of $D D O$ in the postmortem $\mathrm{PFC}$, and is associated with greater prefrontal gray matter and activity during working memory in healthy subjects. ${ }^{22}$ Collectively, the close control exerted by D-Asp on NMDAR-dependent functions and its neurodevelopmental occurrence allow to hypothesize that this D-amino acid could be a potential

\footnotetext{
${ }^{1}$ Ceinge Biotecnologie Avanzate, Naples, Italy; ${ }^{2}$ Department of Molecular Medicine and Medical Biotechnology, University of Naples 'Federico II', Naples, Italy; ${ }^{3}$ Istituto Italiano di Tecnologia, Center for Neuroscience and Cognitive Systems, Rovereto, Italy; ${ }^{4}$ Laboratory of Molecular and Translational Psychiatry, Department of Neuroscience, University School of Medicine 'Federico II', Naples, Italy; ${ }^{5} \mathrm{IEOS}, \mathrm{CNR}$, Naples, Italy; ${ }^{6}$ Department of Biology, University of Naples 'Federico II', Naples, Italy; ${ }^{7} \mathrm{Group}$ of Psychiatric Neuroscience, Department of Neuroscience, Basic Sciences and Sense Organs, University of Bari 'Aldo Moro', Bari, Italy; ${ }^{8}$ pRED, Neuroscience DTA, Hoffman-La Roche, Ltd, Basel, Switzerland; ${ }^{9}$ IRCCS-Fondazione SDN, Via Gianturco, Naples, Italy and ${ }^{10}$ Department of Environmental, Biological and Pharmaceutical Sciences and Technologies, Second University of Naples (SUN), Caserta, Italy. Correspondence: Dr F Errico, Ceinge Biotecnologie Avanzate, Via G. Salvatore, 486, 80145 Naples, Italy or Dr A Gozzi, Istituto Italiano di Tecnologia, Center for Neuroscience and Cognitive Systems, Corso Bettini, 31, 38068 Rovereto, Italy.

E-mail: erricof@ceinge.unina.it or alessandro.gozzi@iit.it

${ }^{11}$ Share co-first authorship.

${ }^{12}$ Share co-last authorship.

Received 4 August 2014; revised 19 December 2014; accepted 19 December 2014
} 
physiological mediator of some of the NMDAR-related processes involved in SCZ. Consistently, we recently described a substantial reduction of D-Asp and of its $\mathrm{N}$-methyl derivative, NMDA, in postmortem PFC of SCZ patients, compared with healthy individuals. $^{23}$

In the present study, we investigated the molecular determinants of the altered D-Asp brain content previously described in SCZ patients. Moreover, in an effort to backtranslate the human findings, we used $\mathrm{Ddo}^{-1-}$ mice to demonstrate that increased DAsp levels, since perinatal phase, can attenuate PCP-induced SCZlike behaviors and their underlying circuital effectors, and affect the development of cortico-hippocampal connectivity networks, reported to be involved in SCZ. ${ }^{24,25}$ Overall, our data suggest a role for this endogenous NMDAR agonist in brain circuits and behaviors associated to SCZ.

\section{MATERIALS AND METHODS}

\section{Human tissue collection}

PFC samples from postmortem brains of non-psychiatrically ill individuals (Ctrl) and subjects with SCZ were obtained from the brain bank of the Institute of Psychiatry, King's College London, London, UK. All tissue collection and processing was carried out under the regulations and licences of the Human Tissue Authority and in accordance with the Human Tissue Act of 2004. Clinical diagnosis of SCZ was performed according to DSMIII-R criteria. Demographic characteristics of control and SCZ subjects are described in Supplementary Table S1. Unpaired Student's $t$-tests were used to determine if the diagnostic groups differed for demographic factors: age, gender, postmortem delay and RNA integrity number (RIN, see Supplementary Table S1).

Quantitative reverse transcription-polymerase chain reaction analysis in humans

Total RNA extraction, RIN assessment, cDNA synthesis and quantitative reverse transcription-polymerase chain reaction (qRT-PCR) amplification are described in Supplementary Methods. All measurements from each subject were performed in duplicate. Changes in DDO mRNA expression of SCZ, compared with Ctrl, were calculated using the relative quantification method $\left(2^{-\Delta \Delta C t}\right)$ and used as dependent variable. Data were analyzed using analysis of covariance with diagnosis as the predictor. Postmortem delay was modeled as covariate of no interest.

\section{Methylation analysis}

Methylation status of the putative $D D O$ promoter was assessed through a strategy on the basis of the locus-specific amplification of bisulfite-treated genomic DNA, as described in Supplementary Methods. Data were analyzed using analysis of covariance with diagnosis as the predictor. Postmortem delay was modeled as covariate of no interest.

\section{Animals}

Knockout male mice for the $D d o$ gene were generated and genotyped by PCR as described previously. ${ }^{26}$ Male C57BL/6-J mice were used to test the effects of 1-month oral administration of D-Asp as previously described. ${ }^{22}$ Housing conditions of mice were described in Supplementary Methods.

\section{qRT-PCR analysis in mice}

Ddo mRNA expression levels were measured in the PFC of C57BL/6-J mice after chronic treatment with olanzapine or haloperidol. Olanzapine (Zyprexa, Eli Lilly and Company, Indianapolis, IN, USA) was dissolved in distilled water. Haloperidol (Sigma-Aldrich, St. Louis, MO, USA) was dissolved in a solution of $10 \%$ acetic acid in saline and the $\mathrm{pH}$ was brought to 6.0 with $1 \mathrm{M} \mathrm{NaOH}$. Olanzapine and haloperidol were intraperitoneally injected daily, for 3 weeks, to 2-month-old C57BL/6 male mice (Harlan Laboratories, Indianapolis, IN, USA) at the dose of $10 \mathrm{mg} \mathrm{kg}^{-1}$ and $1 \mathrm{mg} \mathrm{kg}^{-1}$, respectively, in a volume of $10 \mathrm{ml} \mathrm{kg}^{-1}$. Ninety minutes after the last injection, mice chronically treated with $1 \mathrm{mg} \mathrm{kg}^{-1}$ haloperidol $(n=6), 10 \mathrm{mg} \mathrm{kg}^{-1}$ olanzapine $(n=6)$ or their respective vehicles $(n=5)$ were killed and the PFC dissected out within $20 \mathrm{~s}$ on an ice-cold surface. Dopamine $D 2 R$ mRNA expression levels were measured in the striatum of naive $\mathrm{Ddo}^{+/+}$and $D \mathrm{do}^{-/-}$mice while Homer1a, Homer1b and PSD-95 mRNA expression levels were measured in the PFC of the same animals. Total RNA extraction, CDNA synthesis and qRT-PCR amplification for each of the targets described above were performed as described in Supplementary Methods. All reactions were performed in duplicates with no-template and no-reverse transcription reactions as negative controls. To determine the relative gene expression, the delta delta $\mathrm{Ct}(\Delta \Delta \mathrm{Ct})$ method was used. After the qPCR reaction, melting-curve analysis was performed to confirm the specificity of the transcript. Data were analyzed using Student's $t$-test.

\section{PCP-induced motor activity}

The procedure used has been previously described. ${ }^{19}$ PCP (Sigma, St Louis, MO, USA) was dissolved in distilled water at the dose of 3 and $6 \mathrm{mg} \mathrm{kg}^{-1}$ in a volume of $10 \mathrm{ml} \mathrm{kg}^{-1}$. After $1 \mathrm{~h}$ of habituation to the test cage $(35 \times 25 \times 30 \mathrm{~cm}), \quad$ PCP $\left(3\right.$ and $\left.6 \mathrm{mg} \mathrm{kg}^{-1}\right)$ or vehicle were injected intraperitoneally to male 3 -month-old $\mathrm{Ddo}^{+/+}$and $\mathrm{Ddo} \mathrm{o}^{-/-}$mice and locomotion, expressed in $\mathrm{cm}$, recorded over $1 \mathrm{~h}$ by using a computerized video tracking system (Videotrack; Viewpoint, Lyon, France). Motor response to PCP was evaluated by three-way analysis of variance (ANOVA; genotype $\times$ treatment $\times$ time) with repeated measures, followed by twoway ANOVA (genotype $\times$ time) with repeated measures.

\section{Prepulse inhibition of the startle reflex under PCP treatment}

$\mathrm{Ddo}^{-1-}$ and $\mathrm{D}$-Asp-treated mice, and their respective control groups (Ddo ${ }^{+/+}$and $\mathrm{H}_{2} \mathrm{O}$-treated mice, respectively), were assigned to receive either PCP ( 3 and $6 \mathrm{mg} \mathrm{kg}^{-1}$ ) or vehicle (balanced for genotype and startle chamber assignment) and placed in a Plexiglas cylinder within the startle chamber $10 \mathrm{~min}$ after intraperitoneal injection. Prepulse inhibition (PPI) was measured using an SR-Lab System as previously described. ${ }^{28}$ We chose to test $70,74,78$ and $82 \mathrm{~dB}$ prepulse sounds $(5,9,13$ and $17 \mathrm{~dB}$ above background, respectively). PPI data were analyzed within genotype using two-way ANOVA (treatment $\times$ prepulse sound levels) with repeated measures.

Functional and pharmacological magnetic resonance imaging Resting-state and pharmacological functional magnetic resonance imaging $(\mathrm{fMRI})^{29,30}$ were performed on male $3-4$-month-old $D d 0^{-1-}$ mice $(n=9)$ and $D \mathrm{do}^{+/+}$littermates $(n=12)$ as described in Supplementary Methods. An additional pharmacological fMRI study was carried out on 4-month-old male C57BL/6-J mice treated with D-Asp $(n=10)$ or water $(n=10)$ for 1 month. Briefly, mice were intubated, artificially ventilated and imaged under halothane $(0.7 \%)$ anesthesia. Mean blood pressure, $\mathrm{p}_{\mathrm{a}} \mathrm{CO}_{2}$ and $\mathrm{p}_{\mathrm{a}} \mathrm{O}_{2}$ levels were recorded to rule out non-physiological states. MRI acquisitions were carried out at 7.0 Tesla. For each session, high-resolution anatomical images were followed by a co-centered single-shot BOLD fMRI time series. The functional effect of PCP was mapped using a pharmacological fMRI as previously described. ${ }^{11,31,32} \mathrm{fMRI}$ time series were sensitized to cerebral blood volume using a blood-pool contrast agent, and $15 \mathrm{~min}$ later each subject received an intra-arterial injection of PCP $\left(1 \mathrm{mg} \mathrm{kg}^{-1}\right)$. To assess the modulatory role of $\mathrm{D}$-Asp elevation in wild-type mice, an additional pharmacological fMRI study with PCP was performed in C57BL/6-J mice exposed to D-Asp (20 mM in tap water) or vehicle (plain water) for 1 month ( $n=10$ each group).

Inter-strain differences in resting-state fMRI (rsfMRI) correlation networks were mapped and quantified using a seed-based approach as recently described. ${ }^{30,33}$ Small a priori seed regions were chosen to cover anteroposterior cortical and hippocampal networks. The fMRI response to PCP was mapped and quantified as previously described. ${ }^{11,32,34}$ Relative cerebral blood volume time series before $(8 \mathrm{~min})$ and after drug or vehicle injections $(24 \mathrm{~min})$ were extracted and voxel-wise group statistics were performed using FEAT Version 5.63 with $0.5 \mathrm{~mm}$ spatial smoothing and family-wise cluster correction threshold of 0.001 .

\section{RESULTS}

DDO mRNA expression and methylation of the DDO gene in the postmortem SCZ brain

We have previously found reduced levels of D-Asp and NMDA in the postmortem PFC of patients with SCZ. ${ }^{23}$ Because D-Asp concentration is regulated by DDO, ${ }^{26,35,36}$ we measured the levels of DDO mRNA in the PFC of SCZ patients by qRT-PCR. Statistical analysis revealed a significant increase in DDO mRNA of patients 

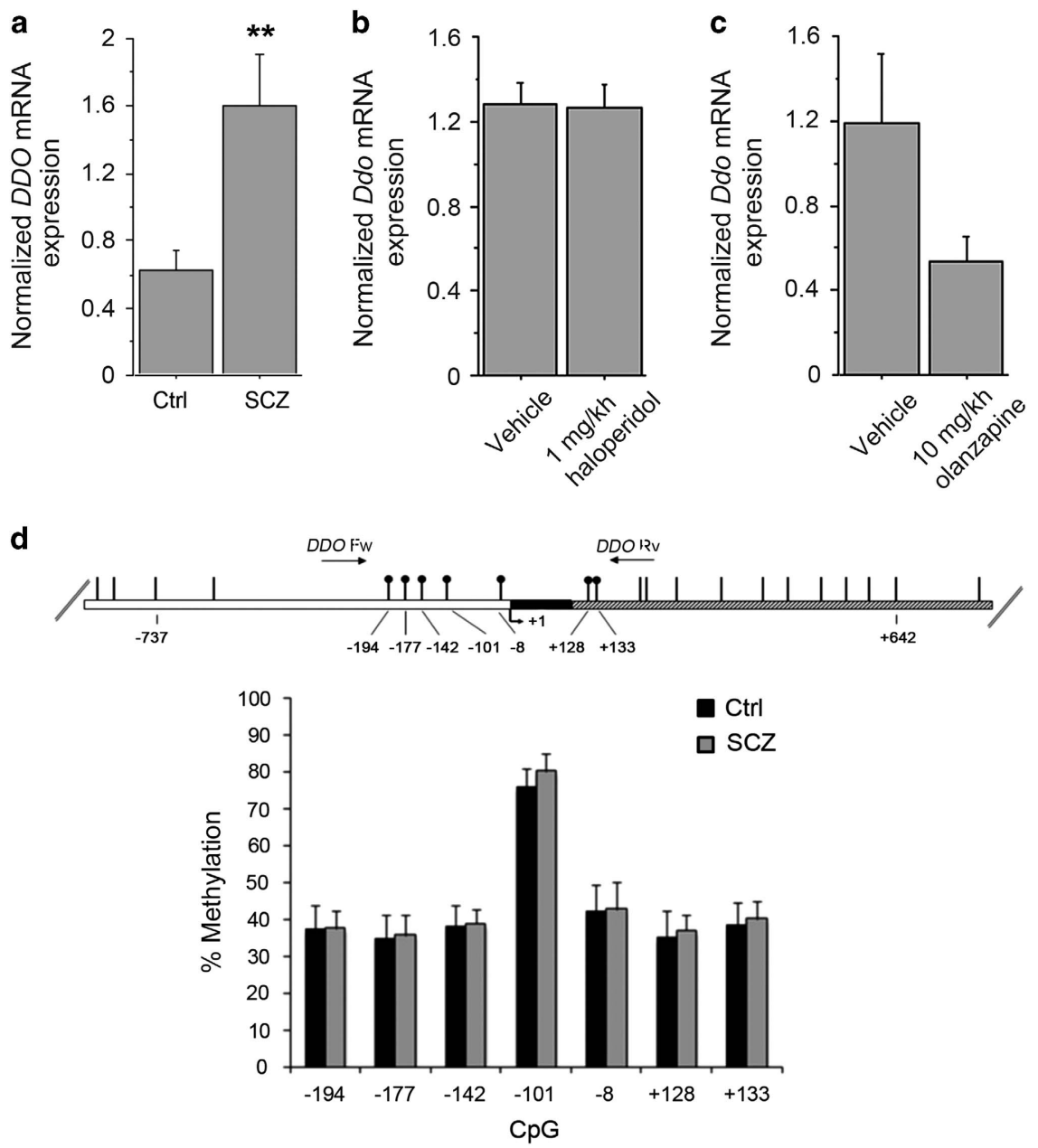

Figure 1. DDO mRNA expression and methylation of the $D D O$ gene in the postmortem schizophrenia (SCZ) brain. (a) Analysis of $D D O$ mRNA expression was performed by quantitative reverse transcription (qRT)-PCR in the PFC of SCZ patients $(n=10)$ and control individuals (Ctrl, $n=11$ ). Quantity means of transcript were normalized to the geometric mean of three housekeeping genes. (b and $\mathbf{c})$ Expression of Ddo mRNA, analyzed by qRT-PCR, in the PFC of mice on treatment with (b) $1 \mathrm{mg} \mathrm{kg}^{-1}$ haloperidol $(n=6)$ or vehicle $(n=5) ;(\mathbf{c}) 10 \mathrm{mg} \mathrm{kg}{ }^{-1}$ olanzapine $(n=6)$ or vehicle $(n=5)$. (d) DDO gene methylation analysis by NGS. The top panel shows the structure of the putative promoter of human $D D O$ gene. The transcriptional start site $(+1)$ is indicated by an arrow. The putative regulatory upstream region (white box), exon (black) and first intron (striped box) are indicated. The primer positions used for methylation analysis are indicated by arrows (DDO Fw and DDO Rv). Vertical bars represent the relative positions of each CpG site. Black circles represent the CpG sites analyzed (CpG $-194,-177,-142$, $-101,-8,+128$ and +133 ). The bar graph below shows the methylation degree of single CpG sites at DDO promoter in the PFC of 14 SCZ patients (gray bars) and 14 Ctrl subjects (black bars) at each CpG site. ${ }^{* *} P<0.01$, ANCOVA. All the values are expressed as mean \pm s.e.m. DDO, D-aspartate oxidase; PFC, prefrontal cortex.

with SCZ, compared with healthy subjects $(P=0.0020$, analysis of covariance with covariance for postmortem delay, Figure 1a). This result suggests that reduced levels of free D-Asp found in the PFC of SCZ samples could depend on greater DDO mRNA expression. To rule out an indirect modulatory contribution of chronic antipsychotic treatment on the expression of DDO mRNA, we chronically treated C57BL/6-J mice with two of the most widely used antipsychotics: haloperidol and olanzapine. No significant change in Ddo mRNA levels was detected in the PFC of mice treated with $1 \mathrm{mg} \mathrm{kg}^{-1}$ haloperidol or $10 \mathrm{mg} \mathrm{kg}^{-1}$ olanzapine, compared with the respective vehicle-treated animals $(P>0.05$ per each treatment, Student's $t$-test; Figures $1 \mathrm{~b}$ and $\mathrm{c})$. This finding suggests that the alteration in DDO mRNA content may represent a direct pathophysiological correlate to SCZ rather than an epiphenomenon due to pharmacological medications. Finally, we evaluated whether the increase of DDO mRNA levels in patients could be associated with changes in the methylation state of $D D O$, through a bisulfite-seq analysis in the postmortem samples extracted from PFC. We analyzed the methylation state of seven
CpG sites $(-194,-177,-142,-101,-8,+128$ and +133$)$ lying in the putative promoter region of $D D O$ surrounding the transcription start site that spans from -199 to +177 nucleotide positions (Figure 1d). Statistical analysis showed no significant difference in the methylation degree between patients and controls $(P>0.05$ per each CpG site, analysis of covariance with covariance for postmortem delay), thus suggesting that the changes in DDO mRNA levels found in the PFC of SCZ patients may not depend on specific methylation pattern associated with the diagnosis. Finally, we also performed a next generation sequencing analysis that allowed us to exclude the occurrence of relevant alterations in the DDO gene (see Supplementary Information).

Schizophrenia-like behavior induced by PCP in $D d o^{-/-}$mice $D d o^{-1-}$ mice are characterized by a 10 - to 20 -fold increase of endogenous $\mathrm{D}$-Asp levels in several brain regions including the cortex, hippocampus, striatum, cerebellum and olfactory bulbs. $^{37,38}$ To evaluate the effect of increased D-Asp levels on SCZ-like behaviors, we challenged $\mathrm{Ddo}^{-1-}$ animals with PCP. On 
the basis of its antagonistic action on NMDARs, PCP is the psychotomimetic drug that best mirrors the symptomatology of SCZ, in humans, ${ }^{39,40}$ primates and rodents. ${ }^{41-44}$ We first tested PCP's psychostimulant motor responses at different doses (3 or $6 \mathrm{mg} \mathrm{kg}^{-1}$; Figure 2a). The increase in locomotion exerted by $3 \mathrm{mg} \mathrm{kg}^{-1}$ PCP was comparable between $\mathrm{Ddo}^{+/+}$and $\mathrm{Ddo}^{-1-}$ mice (three-way ANOVA with repeated measures: treatment $\times$ genotype, $\left.F_{(1,240)}=0.173, P=0.6789\right)$, whereas a significant genotype $\times$ treatment interaction was observed at $6 \mathrm{mg} \mathrm{kg}^{-1}$ PCP $\left(F_{(1,240)}=6.947, P=0.0113\right)$. At this dose, PCP also produced an attenuated motor hyperactivity in $D d o^{-/-}$mice, compared with wild-type littermates (two-way ANOVA with repeated measures: genotype effect, $\left.F_{(1,120)}=6.952, P=0.0145\right)$. We next investigated the effect of PCP on sensorimotor gating properties of $\mathrm{Ddo}^{-/-}$mice by using a PPI paradigm (Figures $2 \mathrm{~b}$ and $\mathrm{c}$ ). Interestingly, we found that $3 \mathrm{mg} \mathrm{kg}^{-1} \mathrm{PCP}$ significantly lowered PPI in $\mathrm{Ddo}^{+/+}$(two-way ANOVA with repeated measures: treatment effect, $\left.F_{(1,54)}=4.906, P=0.0399\right)$ but not in $D d o^{-1-}$ mice, in which a comparable attenuation of the startle amplitude between PCPtreated and untreated animals was observed $\left(F_{(1,54)}=1.668\right.$, $P=0.2129$ ) (Figure 2b). On the contrary, at the dose of $6 \mathrm{mg} \mathrm{kg}^{-1}$, PCP induced a substantial disruption of PPI in both genotypes (treatment effect: $D d o^{+/+}, F_{(1,54)}=6.919, P=0.0170 ; D_{d o}^{-1-}$, $\mathrm{F}_{(1,54)}=6.343, P=0.0215$; Figure $\left.2 \mathrm{c}\right)$. Taken together, these results point at a reduced reactivity to PCP-induced psychotomimetic behaviors in $D d^{-1-}$ animals.

To further evaluate the effect of genetically driven D-Asp elevation, we investigated both basal and PCP-evoked expression of genes coding postsynaptic density proteins involved in the regulation of glutamatergic signaling, such as Homer1a, Homer1b and PSD-95, ${ }^{45}$ in the brain of Ddo ${ }^{-1-}$ mice. Consistent with our behavioral findings, alteration in the functional expression of these genes was modified in $D d o^{-1-}$ mice, as seen with three complementary approaches (that is, in situ hybridization, qRT-PCR and western blotting, see Supplementary Information and Supplementary Figure S1). Besides its well-established NMDAR antagonism, PCP also acts as a D2 receptor (D2R)-like agonist. ${ }^{46-48}$ We performed a battery of molecular and behavioral tests that revealed a preserved D2R neurotransmission in $D d o^{-1-}$ mice, thus corroborating a glutamatergic origin for the different responsivity to PCP observed in Ddo ${ }^{-1-}$ mice (see Supplementary Information and Supplementary Figure S2).

fMRI response induced by PCP in Ddo ${ }^{-1-}$ mice

Because D-Asp can modulate NMDAR-related functions, ${ }^{18-21,38}$ we used $D d o^{-1-}$ mice to assess whether genetically driven $\mathrm{D}$-Asp elevation can modulate the aberrant neurofunctional cascade underlying the psychotomimetic effect of PCP. To this purpose, we used $\mathrm{fMRl}$ to map the neural substrates recruited by a subanesthetic dose of PCP (intravenous $1 \mathrm{mg} \mathrm{kg}^{-1}$ ). Consistent with rodent and human imaging studies, ${ }^{10,11,49,50}$ control mice showed a robust cortico-limbo-thalamic $\mathrm{fMRI}$ response to the drug, with a prominent involvement of the prefrontal-orbitofrontal, cingulate and visual cortex, ventral hippocampus and mediodorsal thalamic nuclei (Figures $3 a, c$ and d). By contrast, a generalized attenuation of PCP-induced fMRI response was observed in Ddo ${ }^{-/-}$mice with respect to wild-type animals (Figures $3 b-d$ ). Quantification of the effect in representative volume of interest revealed the presence of a statistically significant attenuation in several brain regions, including prefrontal, orbitofrontal anterior and posterior (retrosplenial) cingulate, visual and parietal cortex and ventral hippocampus ( $P<0.05$ in all regions, Student's $t$-test). Attenuation in thalamic areas was similarly apparent, and very close to statistical significance $(P=0.051$, Student's $t$-test; Figure $3 d)$. Overall, these results suggest that a challenge with PCP in $D d o^{-1-}$ animals is associated with consistent alterations of blood flow in brain areas known to be involved in the pathophysiology a

$D d o^{+/+}$, vehicle $\Delta D d o^{+/+}, 3 \mathrm{mg} / \mathrm{kg} \mathrm{PCP} \square D d o^{+/+}, 6 \mathrm{mg} / \mathrm{kg} \mathrm{PCP}$

ODdo-r, vehicle $\triangle D d o^{-/}, 3 \mathrm{mg} / \mathrm{kg}$ PCP $\square D d o^{-/}, 6 \mathrm{mg} / \mathrm{kg} \mathrm{PCP}$

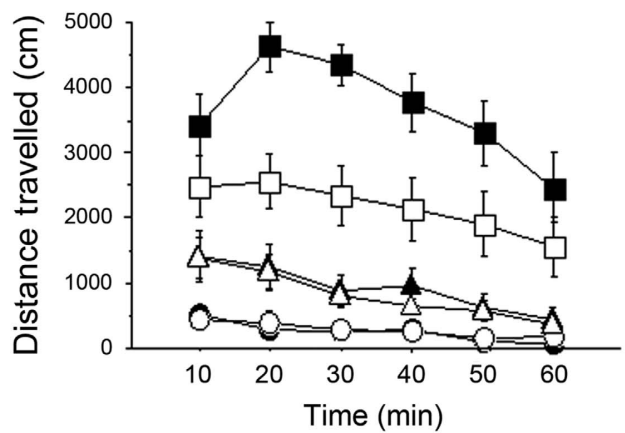

b

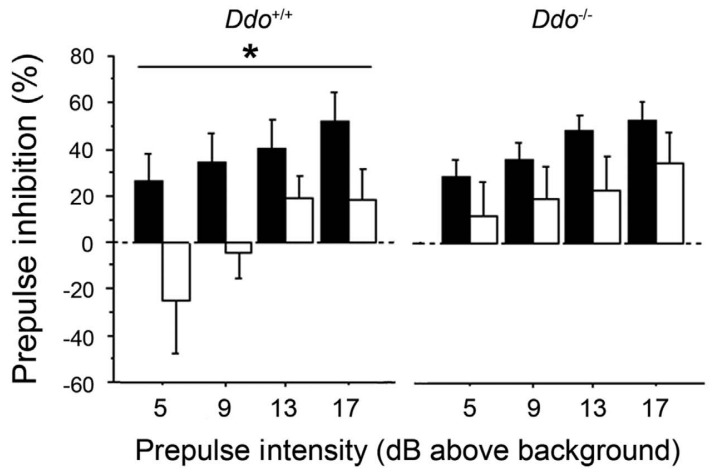

C

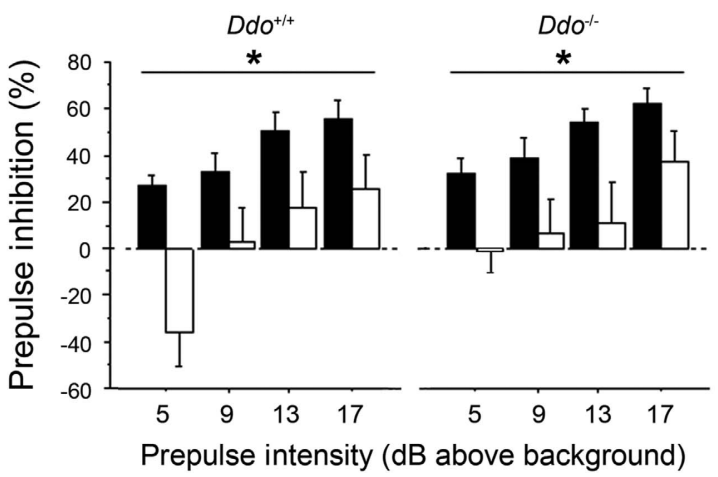

Figure 2. PCP-induced behavioral responses in $D d o^{-/-}$mice. (a) Motor activity induced by $3 \mathrm{mg} \mathrm{kg}^{-1}$ or $6 \mathrm{mg} \mathrm{kg}^{-1} \mathrm{PCP}$ in $D d o^{+/+}$ ( $n=13$ per treatment) and $D d o^{-1-}$ mice $(n=13$ per treatment). Locomotion was expressed as distance traveled, measured in $\mathrm{cm}$ every $10 \mathrm{~min}$ over a $60-\mathrm{min}$ session and presented as time course. (b-c) PPI deficits induced by (b) $3 \mathrm{mg} \mathrm{kg}^{-1}$ or (c) $6 \mathrm{mg} \mathrm{kg}^{-1}$ PCP in $\mathrm{Ddo}^{+++}(n=10$ per treatment $)$ and $D d o^{-/-}$mice $(n=10$ per treatment). Percentage of the PPI was used as dependent variable and measured at different prepulse intensities ( $\mathrm{dB}$ above $65 \mathrm{~dB}$ background level). ${ }^{*} P<0.05$, compared with vehicle control groups. All the values are expressed as the mean \pm s.e.m. DDO, D-aspartate oxidase; PCP, phencyclidine; PPI, prepulse inhibition.

of SCZ. These results suggest that congenital elevation of D-Asp can modulate psychosis-related brain circuits and prevent hyperglutamatergic states produced by non-competitive NMDAR antagonists like PCP. 

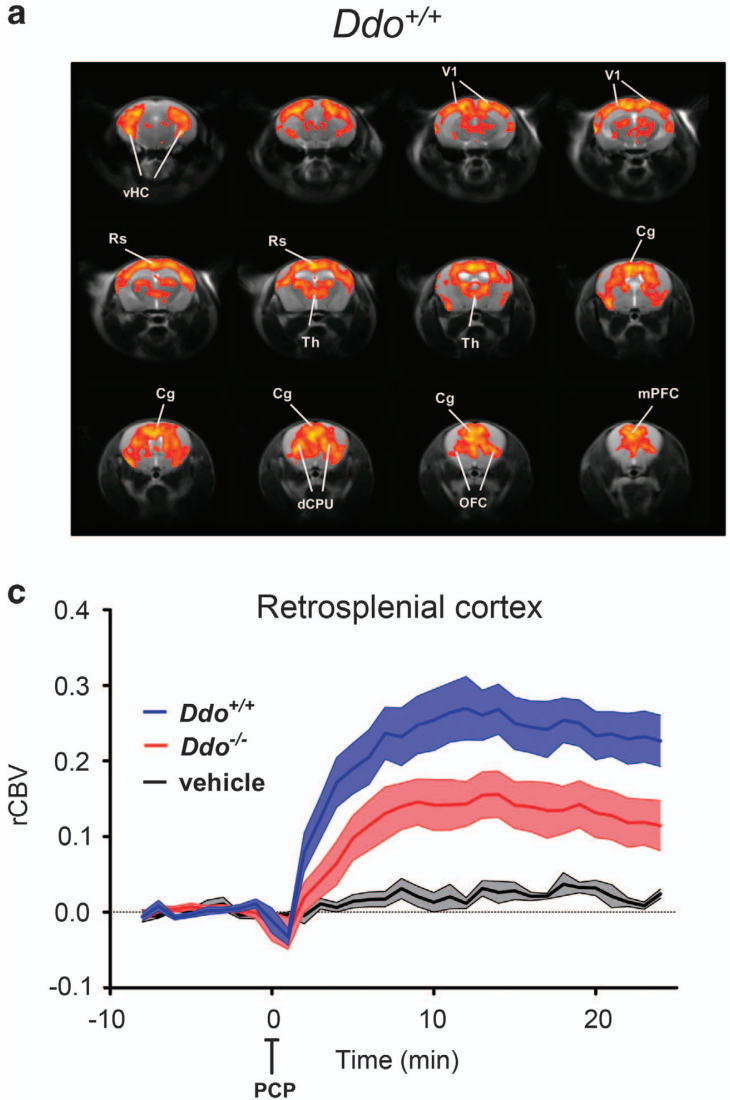

b

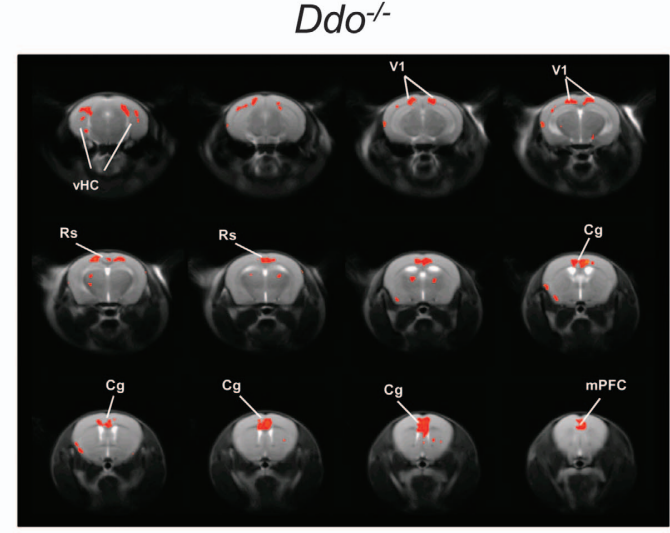

d
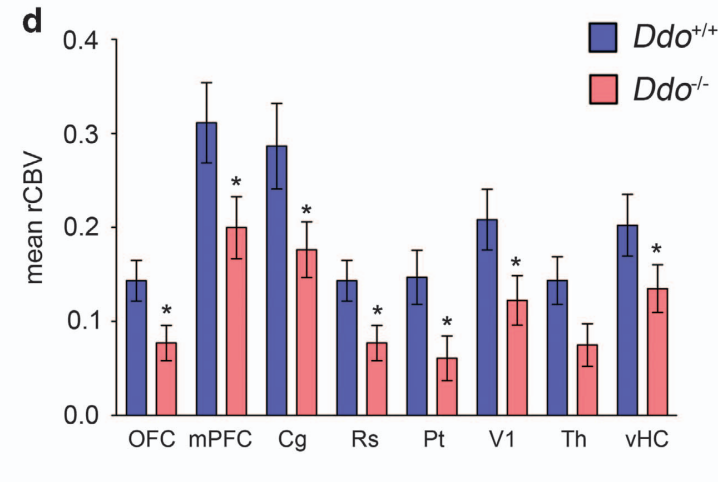

Figure 3. PCP-induced $\mathrm{fMRI}$ response in $D d o^{-/-}$mice. (a and $\mathbf{c}$ ) In $D d o^{+/+}$mice, PCP elicited robust and sustained cortico-limbo-thalamic fMRI activation. (b-d) This effect was strongly attenuated in $D d o^{-\prime-}$ mice. Red/yellow in $\mathbf{a}$ and $\mathbf{b}$ indicates significant $\mathrm{fMRI}$ (rCBV) response to PCP $\left(1 \mathrm{mg} \mathrm{kg}^{-1}\right.$, intra-artery) with respect to vehicle (saline; $3.1<z$-score $<6$, cluster correction threshold $\left.p c=0.001\right)$. ${ }^{*} P<0.05$, Student's $t$-test. Cg, cingulate cortex; dCPU, dorsal caudate putamen; DDO, D-aspartate oxidase; fMRI, functional magnetic resonance imaging; mPFC, medial prefrontal cortex; OFC, orbitofrontal cortex; PCP, phencyclidine; rCBV, relative cerebral blood volume; Rs, retrosplenial cortex; Th, thalamus; vHc, ventral hippocampus; V1, visual cortex.

\section{Cortico-hippocampal connectivity in $\mathrm{Ddo}^{-1-}$ mice}

Our behavioral and imaging data suggest that D-Asp elevation can modulate in vivo NMDAR function and attenuate the acute psychomimetic effects produced by PCP. However, a possible contribution of D-Asp in SCZ is likely to involve long-term adaptative neuro-behavioral changes. In an attempt to identify circuital substrates that are modulated by chronic D-Asp elevation, we carried out intrinsic functional connectivity mapping in Ddo ${ }^{-1-}$ mice using rsfMRI. We recently showed that the mouse brain contains distributed functionally coherent networks analogous to those observed in primates and humans, including plausible homologs of the default mode network. ${ }^{30,33}$ Moreover, reduced cortico-hippocampal connectivity has been reported in SCZ patients. ${ }^{2,25}$ Cortico-hippocampal connectivity was mapped with respect to a bilateral seed region placed in ventral hippocampus (subiculum), a key component of a distributed fronto-hippocampal network that appears to be conserved in rodents and humans. ${ }^{30,51}$ The connectivity profile of the hippocampus in control mice highlighted the involvement of frontal and cingulate cortices (Figure 4a), in agreement with previous reports. ${ }^{30,33,51}$ Interestingly, although the strength of hippocampal-frontal connectivity was similar in the two genotypes, the connectional profile of this region in $D d o^{-1-}$ mice appeared to exhibit a wider and stronger involvement of peri-hippocampal and parietal somatosensory areas $(P<0.01$, Student's $t$-test; Figures $4 \mathrm{~b}$ and $c)$. We detected no significant confounding effect of genotype on depth of anesthesia during $\mathrm{fMRI}$ as assessed by the amplitude of cortical BOLD signal fluctuation, ${ }^{33,52}$ which was comparable in the two genotypes $(62.9 \pm 2.9$ and $65.4 \pm 2.9$, respectively, $P=0.49$, Student's $t$-test). These results highlight a pervasive role of nonphysiological D-Asp brain levels in $\mathrm{Ddo}^{-/-}$animals, in shaping cortico-hippocampal connectivity, a finding of potential translational interest in the light of reports of reduced rsfMRI hippocampal-temporal cortical connectivity in SCZ. ${ }^{25}$

Effect of D-aspartate supplementation on PCP-induced responses In an attempt to dissect the constitutive contribution of D-Asp elevation from its acute effects in the normally developed brain, we explored whether oral supplementation of exogenous D-Asp to adult wild-type C57BL/6-J mice is sufficient to counteract the sensorimotor gating deficits and $\mathrm{fMRI}$ response to PCP. Oral administration of D-Asp ( $20 \mathrm{~mm}$ in tap water) for 1 month produces an $\sim 2-5$-fold increase in the brain D-Asp content, ${ }^{38}$ a level sufficient to modulate several NMDAR-mediated processes including synaptic plasticity and memory. ${ }^{18,19,21,22}$ First, we evaluated the effect of $\mathrm{PCP}$, at the dose of 3 or $6 \mathrm{mg} \mathrm{kg}^{-1}$, on PPI in C57BL/6-J mice pretreated for 1 month with D-Asp or $\mathrm{H}_{2} \mathrm{O}$. Statistical analysis showed that $3 \mathrm{mg} \mathrm{kg}^{-1} \mathrm{PCP}$ produced an overall effect on the inhibition of the startle in mice (three-way ANOVA with repeated measures: $\left.\mathrm{F}_{(1,99)}=4.557, P=0.0403\right)$. However, pretreatment with $\mathrm{D}$-Asp did not significantly alter the PPI deficits induced by PCP (D-Asp pretreatment effect: $F_{(1,99)}=2.386$, $P=0.1320$; D-Asp pretreatment $\times P C P$ treatment: $F_{(1,99)}=0.026$, $P=0.8726$ ) (Figure 5a). We found similar results after treatment with $6 \mathrm{mg} \mathrm{kg}^{-1} \mathrm{PCP}$. At this dose, a stronger disruption of sensorimotor gating was observed $\left(F_{(1,102)}=21.036, P<0.0001\right)$, 
a

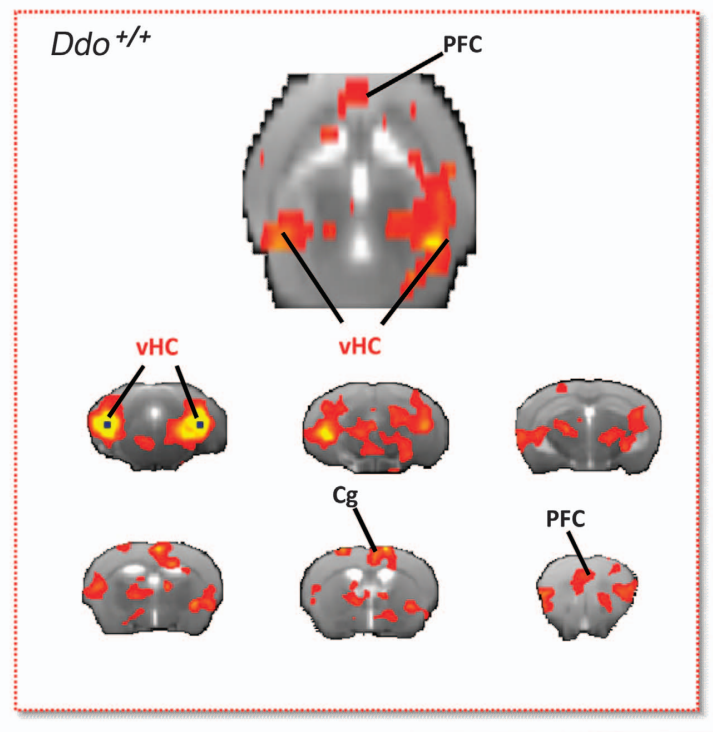

b

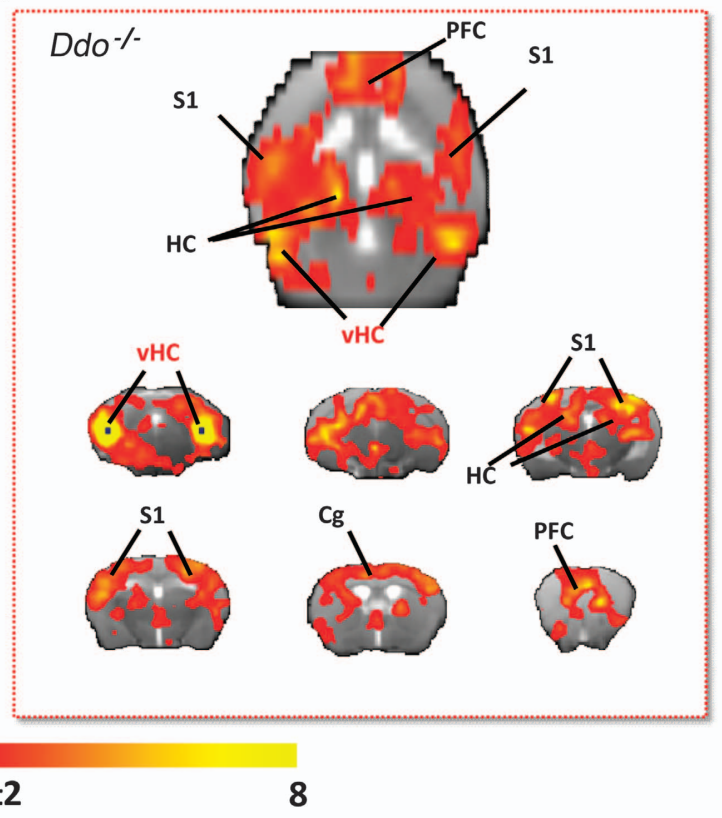

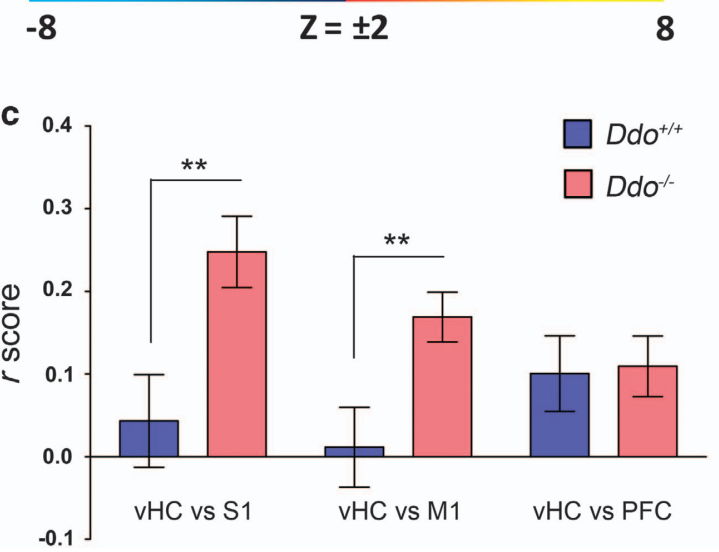

Figure 4. Cortico-hippocampal connectivity in $D d o^{-/-}$mice. Transverse and coronal brain section heat maps showing voxels for which the fMRI BOLD signal was significantly correlated with the ventral hippocampus (seed regions in black) in (a) Ddo ${ }^{+/+}$and (b) Ddo ${ }^{-/-}$mice. The $z-$ score indicates the strength of the correlation. (c) A stronger and more widespread profile of cortical (somatosensory) hippocampal connectivity was apparent in $D d o^{-1-}$ mice. Strength ( $r$-score) of cortico-hippocampal connectivity in representative regions of interest of $D_{d o^{++}}$and $D d o^{-1-}$ mice. ${ }^{* *} P<0.01$, Student's $t$-test. Cg, cingulate cortex; DDO, D-aspartate oxidase; fMRl, functional magnetic resonance imaging; PFC, prefrontal cortex; S1, somatosensory (parietal) cortex; vHc, ventral hippocampus; V1, visual cortex.

an effect that however was not affected by pretreatment with DAsp (D-Asp pretreatment effect: $F_{(1,102)}=0.732, P=0.3983$; D-Asp pretreatment $\times P C P \quad$ treatment: $\quad F_{(1,102)}=0.017, \quad P=0.8960$; Figure $5 b$ ). We then assessed the $\mathrm{fMRI}$ response induced by PCP after chronic D-Asp administration. Both D-Asp- and $\mathrm{H}_{2} \mathrm{O}$-treated mice exhibited a robust cortico-limbo-thalamic fMRI response to the drug, with a prominent involvement of the prefrontalorbitofrontal, cingulate and visual cortex, ventral hippocampus and mediodorsal thalamic nuclei (Figures $5 \mathrm{c}$ and d). However, no statistically significant inter-group difference in the response to PCP was observed either at the voxel level $(z>1.6$, cluster corrected at $P<0.01$ ) or when integrated at the level of volumes of interest (right panel; $P>0.27$, all regions, Student's $t$-test). Overall, in contrast to what was observed in Ddo ${ }^{-1-}$ mice, D-Asp supplementation failed to produce any significant modulation of PCP-induced PPI and fMRI responses. The lack of inhibitory effect observed suggests that D-Asp elevation in normally developed brains may not be sufficient to prevent SCZ-like hyperglutamatergic state, and points at a putative neurodevelopmental origin for some of the phenotypes observed in $D d^{-1-}$ mice. However, a role for the discrepant D-Asp brain exposure attained with supplementation and genetic deletion of Ddo (2-5- vs 10-20-fold increase ${ }^{38}$ ) cannot be entirely ruled out.

\section{DISCUSSION}

Several studies have linked altered metabolism of the endogenous NMDAR co-agonist D-Ser to the etiopathology of SCZ. Evidence in this direction is given by the observation that $D$-Ser levels are reduced in the blood, cerebrospinal fluid and postmortem brain tissues of patients with SCZ. ${ }^{6,53-55}$ Accordingly, increased mRNA expression and activity of the enzyme responsible for the degradation of this D-amino acid, D-amino acid oxidase, have been observed in the postmortem brain of $\mathrm{SCZ}$ subjects. ${ }^{8,56}$ Recent evidence suggests that the atypical amino acid D-Asp, enriched in the embryo brain, promotes NMDAR-dependent transmission. $^{38}$ Consistent with the hypothesis of NMDAR dysfunction in $\mathrm{SCZ}_{1}{ }^{1-4}$ we have previously found reduced levels of D-Asp in the postmortem PFC of SCZ patients. ${ }^{23}$ In the present study, we found a substantial increase in DDO mRNA levels in the PFC of SCZ patients, thus highlighting a plausible link between overexpression of DDO mRNA and reduced D-Asp levels in SCZ samples. Our data also show that alterations in DDO mRNA are not 
a $\mathrm{H}_{2} \mathrm{O}$, vehicle $\square$ D-Asp, vehicle
$\square \mathrm{H}_{2} \mathrm{O}, 3 \mathrm{mg} / \mathrm{kg}$ PCP $\square$ D-Asp, 3mg/kg PCP

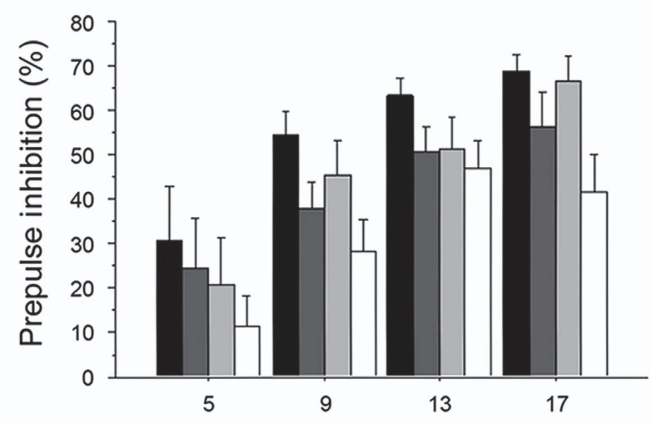

Prepulse intensity ( $\mathrm{dB}$ above background)

C

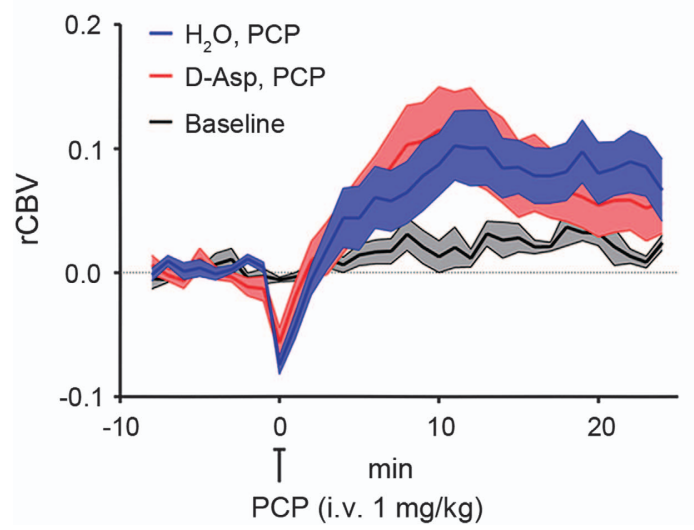

b
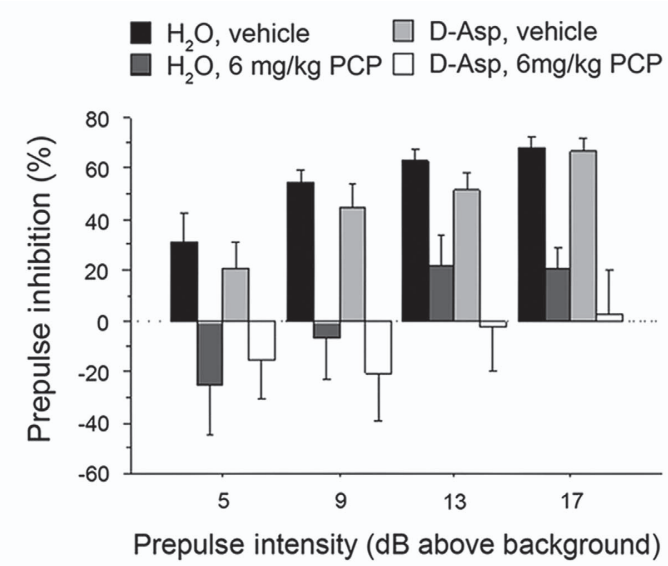

d

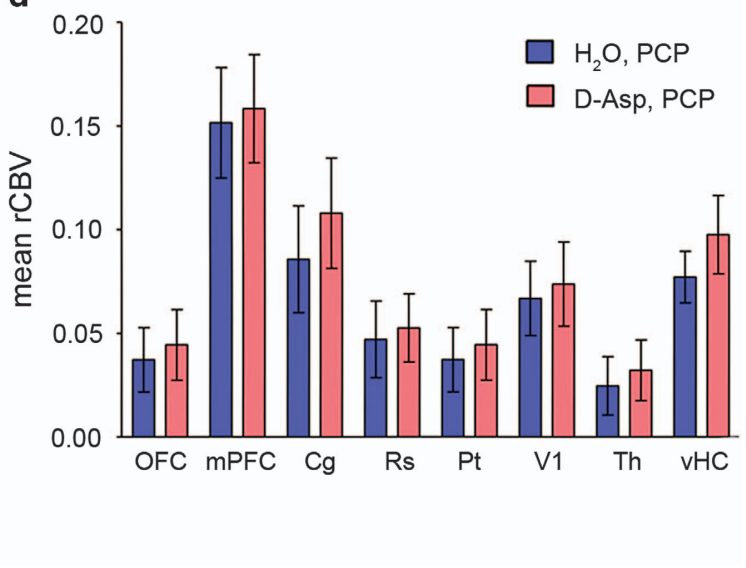

Figure 5. Effect of D-aspartate (D-Asp) supplementation on PCP-induced responses. (a and $\mathbf{b})$ Prepulse inhibition responses to PCP after 1month oral administration of D-aspartate in mice treated with (a) $3 \mathrm{mg} \mathrm{kg}^{-1} \mathrm{PCP}\left(n=10 \mathrm{H}_{2} \mathrm{O} ; n=9 \mathrm{D}-\mathrm{Asp}\right)$ or vehicle $(n=10 \mathrm{H} \mathrm{O} ; n=8 \mathrm{D}-\mathrm{Asp})$, (b) $6 \mathrm{mg} \mathrm{kg}^{-1} \mathrm{PCP}\left(n=10 \mathrm{H}_{2} \mathrm{O} ; n=10 \mathrm{D}-\mathrm{Asp}\right)$ or vehicle $\left(n=10 \mathrm{H}_{2} \mathrm{O} ; n=8 \mathrm{D}-\mathrm{Asp}\right)$. Percentage of the PPI was used as dependent variable and measured at different prepulse intensities (shown as $\mathrm{dB}$ above $65 \mathrm{~dB}$ background level). All the values are expressed as the mean $\pm \mathrm{s}$.e.m. (c and d) PCP-induced fMRI response in D-Asp- and $\mathrm{H}_{2} \mathrm{O}$-treated adult C57BL6/J mice. In both groups of animals, PCP elicited robust and sustained cortico-limbo-thalamic fMRI activation (left and right panels). No statistically significant difference in the inter-group response to PCP was observed either at the voxel level $(z>1.6$, cluster corrected at $P<0.01)$ or when integrated at the level of volumes of interest (right panel; $P>0.27$, all regions, Student's $t$-test). $C g$, cingulate cortex; dCPU, dorsal caudate putamen; fMRI, functional magnetic resonance imaging; $\mathrm{mPFC}$, medial prefrontal cortex; OFC, orbitofrontal cortex; PCP, phencyclidine; PPI, prepulse inhibition; rCBV, relative cerebral blood volume; Rs, retrosplenial cortex; Th, thalamus; vHc, ventral hippocampus; V1, visual cortex.

directly associated with methylation of the CpG sites in the putative promoter region of the gene, as the pattern of methylation was unchanged in the PFC of patients, compared with control subjects. In addition, in keeping with a previous study, ${ }^{57}$ sequencing analysis of the entire DDO gene did not identify any gross genetic variation in our study group. Further investigations on a larger number of subjects are warranted to address this issue more in detail.

To evaluate in a preclinical model the effect of an altered metabolism of D-Asp on SCZ-like manifestations, we tested psychotic-like effect of PCP in Ddo ${ }^{-/-}$mice. We found significantly reduced psychostimulant effect of PCP in $D d o^{-/-}$mice, as shown by their attenuated motor hyperactivity, compared with control littermates. Most importantly, constitutively increased levels of DAsp in knockout animals also produced a reduced sensitivity to PCP-dependent disruption of sensorimotor gating. As the PPI paradigm is used as an endophenotypic trait to assess dysfunction of sensorimotor gating processing in SCZ patients, ${ }^{58}$ the modulation of PCP-induced disruption of PPI in animals characterized by elevated $\mathrm{D}$-Asp levels is of potential translational relevance. To rule out a role for abnormal dopamine D2R neurotransmission in the reduced PCP responsivity observed in $D d o^{-/-}$mice, ${ }^{46-48}$ we treated these animals with selective D2R agonist and antagonist, like quinpirole and haloperidol, respectively. Behavioral studies revealed an intact $D 2 R$ responsivity, supporting the notion that the blunted sensitivity to PCP is not linked to altered D2R transmission, a finding corroborated by the evidence of comparable D2R mRNA and protein levels in the striatum of $\mathrm{Ddo}^{+/+}$and $D d^{-1-}$ mice (see Supplementary Information). We also observed mild changes in gene expression pattern of Homer1a and PSD-95 in knockout brains by in situ hybridization, further suggesting an altered tonic and phasic activation of glutamatergic system by non-physiological D-Asp levels (see Supplementary Information).

In line with behavioral data, fMRI results show that increased DAsp, through its ability to promote NMDAR transmission, strongly inhibited the functional activation elicited by PCP in corticolimbo-thalamic regions of $D d o^{-1-}$ mice. This effect is consistent with previous imaging work showing that pharmacological potentiation of NMDAR function by D-Ser, can effectively inhibit the hyperglutamatergic state produced by NMDAR antagonism ${ }^{32}$ and modulate psychosis-related neurocircuits. Interestingly, oral supplementation of a neurobiologically active dose of D-Asp to

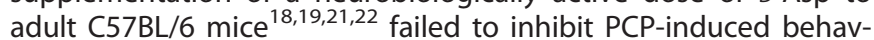
ioral or functional responses. These findings point at a putative 
neurodevelopmental origin for some of the phenotypes observed in $D d o^{-1-}$ mice and suggests that both the time window and duration of increased D-Asp could have a critical role in shaping NMDAR-mediated circuit responsivity. However, differences in brain exposure obtained with supplementation and genetic deletion of Ddo (2-5- vs 10-20-fold increase, respectively ${ }^{38}$ ) can also be invoked to explain these discrepant results, and further research using more effective D-Asp formulations is warranted to address this issue. From a purely pharmacodynamic standpoint, inhibition of DDO activity could be an approach to obtain D-Asp brain exposure exceeding that attainable with oral administration of the amino acid. This may unveil a role for DDO as an attractive target for the development of medications aimed at increasing central exposure of this molecule.

The functional and structural similarities between D-Ser and DAsp and their potential convergence on SCZ pathophysiology have led to the hypothesis that these D-amino acids may be reciprocally linked and share common metabolic pathways. A recent work has indeed revealed lower levels of D-Asp in the forebrain structures of mice lacking the enzyme serine racemase, which synthesizes endogenous D-Ser. ${ }^{60}$ However, neurochemical detection in the PFC did not reveal any change in D-Ser levels in $D d o^{-/-}$mice, compared with $D_{d o^{+/+}}$animals (data not shown). Nevertheless, further studies are required to better evaluate the possible interaction between these two D-amino acids.

Finally, in an attempt to identify circuital substrates that are modulated by constitutive D-Asp elevation and to increase the translational relevance of our findings, we also performed measurement of cortico-hippocampal connectivity in Ddo ${ }^{-1-}$ mice using rsfMRI. ${ }^{30,33}$ Clinical and preclinical evidence supports the presence of cortico-hippocampal dysconnectivity in SCZ, a feature that seems to predominantly affect fronto-cortical areas, ${ }^{24}$ with the additional involvement of large parietal and perihippocampal cortical regions. ${ }^{25}$ Interestingly, although the strength of hippocampal-frontal connectivity was similar in the two genotypes, our rsfMRI measurements suggest that elevated DAsp levels can reshape the connectional profile of the hippocampus, resulting in stronger and more widespread peri-hippocampal and parietal-hippocampal connectivity in knockout brains. A role for embryonic and perinatal D-Asp elevation in modeling the connectivity of hippocampal regions is not surprising in the light of the ability of this D-amino acid to promote hippocampal synaptic plasticity, ${ }^{18,20,21,24}$ dendritic length and spine density in adulthood. ${ }^{22}$ Our data suggest that this feature can alter the connectional profile of this region with neighboring and longrange cortical areas. The presence of enhanced cortico-hippocampal connectivity in a mouse model like $\mathrm{Ddo}^{-/-}$, which shows an overall resiliency to PCP-induced SCZ-like manifestations, is broadly consistent with the impaired cortico-hippocampal brain network organization reported in patients and in preclinical models of SCZ. ${ }^{24,25}$

In conclusion, our data suggest that increased expression of DDO mRNA in the PFC of SCZ patients can result in a corresponding excessive degradation of D-Asp. ${ }^{23}$ We also demonstrate in a preclinical model that constitutive high levels of D-Asp exert a putative protective effect against the SCZ-like symptoms induced by the NMDAR antagonist PCP. Taken together, these findings support a role for D-Asp as a potential vulnerability factor in SCZ. Consistent with a neurodevelopmental hypothesis of $\mathrm{SCZ},{ }^{12,61}$ a putative precocious downregulation of D-Asp levels, associated to abnormal metabolism of this molecule, may have a much greater impact during critical phases of brain development, when D-Asp levels are physiologically high. ${ }^{13,14,16}$ Future studies in mouse models permitting controlled exposure of D-Asp levels during neurodevelopment are warranted to investigate this basic issue.

\section{CONFLICT OF INTEREST}

The authors declare no conflict of interest.

\section{ACKNOWLEDGMENTS}

We thank V. Lucignano, T. Nuzzo and G. Aceto for their excellent technical support, and Dr C. Troakes (Institute of Psychiatry, King's College London, London, UK) for her helpful assistance with tissue collection. AU represents the Mariano Scippacercola Foundation. AU was supported by NARSAD Independent Investigator Grant from the Brain and Behavior Research Foundation (Grant no: 20353). FE was supported by grants from the Italian Ministero dell'Istruzione, dell'Università e della Ricerca (FIRB Call-Program 'Futuro in Ricerca 2010'-Project no RBFR10XCD3) and the Italian Ministero della Salute (Call Giovani Ricercatori 2009_Project no GR-2009-1605759). Also Supported by Epigen Flagship Projects.

\section{REFERENCES}

1 Moghaddam B, Javitt D. From revolution to evolution: the glutamate hypothesis of schizophrenia and its implication for treatment. Neuropsychopharmacology 2012; 37: 4-15.

2 Coyle JT. NMDA receptor and schizophrenia: a brief history. Schizophr Bull 2012; 38: $920-926$.

3 Coyle JT, Tsai G. NMDA receptor function, neuroplasticity, and the pathophysiology of schizophrenia. Int Rev Neurobiol 2004; 59: 491-515.

4 Sawa A, Snyder SH. Schizophrenia: neural mechanisms for novel therapies. Mol Med 2003; 9: 3-9.

5 Kristiansen LV, Huerta I, Beneyto M, Meador-Woodruff JH. NMDA receptors and schizophrenia. Curr Opin Pharmacol 2007; 7: 48-55.

6 Hashimoto K, Engberg G, Shimizu E, Nordin C, Lindstrom LH, lyo M. Reduced $\mathrm{D}$-serine to total serine ratio in the cerebrospinal fluid of drug naive schizophrenic patients. Prog Neuropsychopharmacol Biol Psychiatry 2005; 29: 767-769.

7 Linderholm KR, Skogh E, Olsson SK, Dahl ML, Holtze M, Engberg G et al. Increased levels of kynurenine and kynurenic acid in the CSF of patients with schizophrenia. Schizophr Bull 2012; 38: 426-432.

8 Madeira C, Freitas ME, Vargas-Lopes C, Wolosker H, Panizzutti R. Increased brain D-amino acid oxidase (DAAO) activity in schizophrenia. Schizophr Res 2008; 101: 76-83.

9 Tsai SJ. Central $N$-acetyl aspartylglutamate deficit: a possible pathogenesis of schizophrenia. Med Sci Monit 2005; 11: HY39-HY45.

10 Bifone A, Gozzi A. Neuromapping techniques in drug discovery: pharmacological MRI for the assessment of novel antipsychotics. Expert Opin Drug Discov 2012; 7: 1071-1082.

11 Gozzi A, Large CH, Schwarz A, Bertani S, Crestan V, Bifone A. Differential effects of antipsychotic and glutamatergic agents on the phMRI response to phencyclidine. Neuropsychopharmacology 2008; 33: 1690-1703.

12 Owen MJ, O'Donovan MC, Thapar A, Craddock N. Neurodevelopmental hypoth esis of schizophrenia. Br J Psychiatry 2011; 198: 173-175.

13 Sakai K, Homma H, Lee JA, Fukushima T, Santa T, Tashiro K et al. Emergence of $D$-aspartic acid in the differentiating neurons of the rat central nervous system. Brain Res 1998; 808: 65-71.

14 Wolosker H, D'Aniello A, Snyder SH. D-aspartate disposition in neuronal and endocrine tissues: ontogeny, biosynthesis and release. Neuroscience 2000; 100: 183-189.

15 Schell MJ, Cooper OB, Snyder SH. D-aspartate localizations imply neuronal and neuroendocrine roles. Proc Natl Acad Sci USA 1997; 94: 2013-2018.

16 Hashimoto A, Kumashiro S, Nishikawa T, Oka T, Takahashi K, Mito T et al. Embryonic development and postnatal changes in free $\mathrm{D}$-aspartate and $\mathrm{D}$-serine in the human prefrontal cortex. J Neurochem 1993; 61: 348-351.

17 Van Veldhoven PP, Brees C, Mannaerts GP. D-aspartate oxidase, a peroxisomal enzyme in liver of rat and man. Biochim Biophys Acta 1991; 1073: 203-208.

18 Errico F, Nistico R, Napolitano F, Mazzola C, Astone D, Pisapia T et al. Increased D-aspartate brain content rescues hippocampal age-related synaptic plasticity deterioration of mice. Neurobiol Aging 2011; 32: 2229-2243.

19 Errico F, Rossi S, Napolitano F, Catuogno V, Topo E, Fisone G et al. D-aspartate prevents corticostriatal long-term depression and attenuates schizophrenia-like symptoms induced by amphetamine and MK-801. J Neurosci 2008; 28: 10404-10414.

20 Errico F, Nistico R, Napolitano F, Oliva AB, Romano R, Barbieri F et al. Persistent increase of $\mathrm{D}$-aspartate in $\mathrm{D}$-aspartate oxidase mutant mice induces a precocious hippocampal age-dependent synaptic plasticity and spatial memory decay. Neurobiol Aging 2011; 32: 2061-2074.

21 Errico F, Nistico R, Palma G, Federici M, Affuso A, Brilli E et al. Increased levels of d-aspartate in the hippocampus enhance LTP but do not facilitate cognitive flexibility. Mol Cell Neurosci 2008; 37: 236-246. 
22 Errico F, Nistico R, Di Giorgio A, Squillace M, Vitucci D, Galbusera A et al. Free D-aspartate regulates neuronal dendritic morphology, synaptic plasticity, gray matter volume and brain activity in mammals. Transl Psychiatry 2014; 4: e417.

23 Errico F, Napolitano F, Squillace M, Vitucci D, Blasi G, de Bartolomeis A et al. Decreased levels of D-aspartate and NMDA in the prefrontal cortex and striatum of patients with schizophrenia. J Psychiatr Res 2013; 47: 1432-1437.

24 Meyer-Lindenberg A. From maps to mechanisms through neuroimaging of schizophrenia. Nature 2010; 468: 194-202.

25 Zhou Y, Shu N, Liu Y, Song M, Hao Y, Liu H et al. Altered resting-state functional connectivity and anatomical connectivity of hippocampus in schizophrenia. Schizophr Res 2008; 100: 120-132.

26 Errico F, Pirro MT, Affuso A, Spinelli P, De Felice M, D'Aniello A et al. A physiological mechanism to regulate $\mathrm{D}$-aspartic acid and NMDA levels in mammals revealed by D-aspartate oxidase deficient mice. Gene 2006; 374: 50-57.

27 Chiba S, Hashimoto R, Hattori S, Yohda M, Lipska B, Weinberger DR et al. Effect of antipsychotic drugs on DISC1 and dysbindin expression in mouse frontal cortex and hippocampus. J Neural Transm 2006; 113: 1337-1346.

28 Errico F, Santini E, Migliarini S, Borgkvist A, Centonze D, Nasti V et al. The GTPbinding protein Rhes modulates dopamine signalling in striatal medium spiny neurons. Mol Cell Neurosci 2008; 37: 335-345.

29 Ferrari L, Turrini G, Crestan V, Bertani S, Cristofori P, Bifone A et al. A robust experimental protocol for pharmacological fMRI in rats and mice. $J$ Neurosci Methods 2012; 204: 9-18.

30 Sforazzini F, Schwarz AJ, Galbusera A, Bifone A, Gozzi A. Distributed BOLD and CBV-weighted resting-state networks in the mouse brain. Neuroimage 2013; 87: 403-415.

31 Dodero L, Damiano M, Galbusera A, Bifone A, Tsaftsaris SA, Scattoni ML et al. Neuroimaging evidence of major morpho-anatomical and functional abnormalities in the BTBR T+TF/J mouse model of autism. PLoS One 2013; 8: e76655.

32 Gozzi A, Herdon H, Schwarz A, Bertani S, Crestan V, Turrini G et al. Pharmacological stimulation of NMDA receptors via co-agonist site suppresses fMRI response to phencyclidine in the rat. Psychopharmacology (Berl) 2008; 201: 273-284.

33 Zhan Y, Paolicelli RC, Sforazzini F, Weinhard L, Bolasco G, Pagani F et al. Deficient neuron-microglia signaling results in impaired functional brain connectivity and social behavior. Nat Neurosci 2014; 17: 400-406.

34 Gozzi A, Schwarz A, Crestan V, Bifone A. Drug-anaesthetic interaction in phMRI: the case of the psychotomimetic agent phencyclidine. Magn Reson Imaging 2008; 26: 999-1006.

35 D'Aniello A, Vetere A, Petrucelli L. Further study on the specificity of D-amino acid oxidase and D-aspartate oxidase and time course for complete oxidation of D-amino acids. Comp Biochem Physiol 1993; 105: 731-734.

36 Huang AS, Beigneux A, Weil ZM, Kim PM, Molliver ME, Blackshaw S et al. Daspartate regulates melanocortin formation and function: behavioral alterations in D-aspartate oxidase-deficient mice. J Neurosci 2006; 26: 2814-2819.

37 Errico F, Bonito-Oliva A, Bagetta V, Vitucci D, Romano R, Zianni E et al. Higher free $\mathrm{D}$-aspartate and $\mathrm{N}$-methyl-D-aspartate levels prevent striatal depotentiation and anticipate L-DOPA-induced dyskinesia. Exp Neurol 2011; 232: 240-250.

38 Errico F, Napolitano F, Nistico R, Usiello A. New insights on the role of free D-aspartate in the mammalian brain. Amino Acids 2012; 43: 1861-1871.

39 Allen RM, Young SJ. Phencyclidine-induced psychosis. Am J Psychiatry 1978; 135: 1081-1084.

40 Domino EF. Neurobiology of phencyclidine (Sernyl), a drug with an unusual spectrum of pharmacological activity. Int Rev Neurobiol 1964; 6: 303-347.

41 Javitt DC, Zukin SR, Heresco-Levy U, Umbricht D. Has an angel shown the way? Etiological and therapeutic implications of the PCP/NMDA model of schizophrenia. Schizophr Bull 2012; 38: 958-966.

42 Moghaddam B, Krystal JH. Capturing the angel in 'angel dust': twenty years of translational neuroscience studies of NMDA receptor antagonists in animals and humans. Schizophr Bull 2012; 38: 942-949.

43 Morris BJ, Cochran SM, Pratt JA. PCP: from pharmacology to modelling schizophrenia. Curr Opin Pharmacol 2005; 5: 101-106.

44 Jones CA, Watson DJ, Fone KC. Animal models of schizophrenia. Br J Pharmacol 2011; 164: 1162-1194.
45 de Bartolomeis A, Sarappa C, Buonaguro EF, Marmo F, Eramo A, Tomasetti C et al. Different effects of the NMDA receptor antagonists ketamine, MK-801, and memantine on postsynaptic density transcripts and their topography: role of Homer signaling, and implications for novel antipsychotic and pro-cognitive targets in psychosis. Prog Neuropsychopharmacol Biol Psychiatry 2013; 46: 1-12.

46 Seeman P, Ko F, Tallerico T. Dopamine receptor contribution to the action of PCP, LSD and ketamine psychotomimetics. Mol Psychiatry 2005; 10: 877-883.

47 Kapur S, Seeman P. NMDA receptor antagonists ketamine and PCP have direct effects on the dopamine $\mathrm{D}(2)$ and serotonin 5-HT(2)receptors-implications for models of schizophrenia. Mol Psychiatry 2002; 7: 837-844.

48 Seeman P, Lasaga M. Dopamine agonist action of phencyclidine. Synapse 2005; 58: $275-277$.

49 De Simoni S, Schwarz AJ, O'Daly OG, Marquand AF, Brittain C, Gonzales C et al. Test-retest reliability of the BOLD pharmacological MRI response to ketamine in healthy volunteers. Neuroimage 2013; 64: 75-90.

50 Doyle OM, De Simoni S, Schwarz AJ, Brittain C, O'Daly OG, Williams SC et al. Quantifying the attenuation of the ketamine pharmacological magnetic resonance imaging response in humans: a validation using antipsychotic and glutamatergic agents. J Pharmacol Exp Ther 2013; 345: 151-160.

51 Schwarz AJ, Gass N, Sartorius A, Zheng L, Spedding M, Schenker E et al. The lowfrequency blood oxygenation level-dependent functional connectivity signature of the hippocampal-prefrontal network in the rat brain. Neuroscience 2013; 228: 243-258.

52 Liu X, Zhu XH, Zhang Y, Chen W. Neural origin of spontaneous hemodynamic fluctuations in rats under burst-suppression anesthesia condition. Cereb Cortex 2011; 21: 374-384.

53 Bendikov I, Nadri C, Amar S, Panizzutti R, De Miranda J, Wolosker H et al. A CSF and postmortem brain study of D-serine metabolic parameters in schizophrenia. Schizophr Res 2007; 90: 41-51.

54 Hashimoto K, Fukushima T, Shimizu E, Komatsu N, Watanabe H, Shinoda N et al. Decreased serum levels of D-serine in patients with schizophrenia: evidence in support of the $\mathrm{N}$-methyl-D-aspartate receptor hypofunction hypothesis of schizophrenia. Arch Gen Psychiatry 2003; 60: 572-576.

55 Yamada K, Ohnishi T, Hashimoto K, Ohba H, Iwayama-Shigeno Y, Toyoshima M et al. Identification of multiple serine racemase (SRR) mRNA isoforms and genetic analyses of SRR and DAO in schizophrenia and D-serine levels. Biol Psychiatry 2005; 57: 1493-1503.

56 Verrall L, Walker M, Rawlings N, Benzel I, Kew JN, Harrison PJ et al. d-Amino acid oxidase and serine racemase in human brain: normal distribution and altered expression in schizophrenia. Eur J Neurosci 2007; 26: 1657-1669.

57 Jamra RA, Georgi A, Suliman H, Klein K, Villela AW, Schulze TG et al. No association between the D-aspartate oxidase locus and schizophrenia. Psychiatr Genet 2009; 19: 56.

58 Gottesman II, Gould TD. The endophenotype concept in psychiatry: etymology and strategic intentions. Am J Psychiatry 2003; 160: 636-645.

59 Horio M, Ishima T, Fujita Y, Inoue R, Mori H, Hashimoto K. Decreased levels of free $\mathrm{D}$-aspartic acid in the forebrain of serine racemase (Srr) knock-out mice. Neurochem Int 2013; 62: 843-847.

60 Martineau M, Baux G, Mothet JP. D-serine signalling in the brain: friend and foe. Trends Neurosci 2006; 29: 481-491.

61 Fatemi SH, Folsom TD. The neurodevelopmental hypothesis of schizophrenia, revisited. Schizophr Bull 2009; 35: 528-548.

(c) (1) (2) This work is licensed under a Creative Commons AttributionNonCommercial-ShareAlike 4.0 International License. The images or other third party material in this article are included in the article's Creative Commons license, unless indicated otherwise in the credit line; if the material is not included under the Creative Commons license, users will need to obtain permission from the license holder to reproduce the material. To view a copy of this license, visit http:// creativecommons.org/licenses/by-nc-sa/4.0/

Supplementary Information accompanies the paper on the Translational Psychiatry website (http://www.nature.com/tp) 